\title{
Archives, Bureaucracies, Architecture: Now You See Me, Now You Don't
}

\author{
Anna-Maria Meister
}

Editorial Summary: In her text, Anna-Maria Meister focuses on the production and dissemination of norms, normed objects, standards, bureaucratic measures, and administrative processes as social desires in German modern architecture. She states that we must treat them as formal and political acts of "Gestaltung " and critically probe their ideological intent and human consequence since the regulations in place, the order imagined, or the systems constructed were as formative to what we now know as Modern Architecture, as aesthetics or so-called Avant-Garde architects. As a result, rules and codes are "aesthetic tools « rather than mere »bureaucratic impediments". She claims that it is necessary to research beyond the beaten path to include those contents that are usually left by the wayside, thus revealing and constructing alternative archives and histories. [Ferdinand Ludwig]

Keywords: Archives; Regulation; Norms; Standardization; Activist History; Oral History; Networks; Power Structures; Bureaucracy; Visibility.

What do we see when we look at architecture? And what when looking at its history? These are questions often asked of (and by) architecture historians. And yet, I would argue, they already surmise much of what our task is: a definition of »architecture «, a singular understanding of »history«, and the assumption of visibility. After all, for such a question there needs to be an »architecture « and a "history « that one can even presume to be looking at. While these might sound like sophistic musings, I argue that these are the core concerns in our field - or should be. As a historian and architect, I am interested in the construction of history and the historical construction of architectural production. We know that what we call »history« is not a collection of facts or the remnants of old buildings, but the reconstruction of worldviews. This means that not only do we need to investigate the context of the protagonists or systems we look at, but our own as well - both in practice and in scholarship. Looking at a certain building, image, or file, 
we have to understand the layers of its construction; but furthermore, we also need to understand how that very building, image, or file came to be one that we consider in the first place. Why are certain buildings built? Who decides which are maintained or reconstructed? More importantly, what keeps others from coming into being? It becomes clear that the work of the historian is as much one of making the unseen visible as that of the architect. Where architects imagine new spaces, historians are tasked not only with contextualizing those imaginaries, but with excavating and reconstructing how they became possible - and how others did not.

As historians, we have an obligation to look for those who are often overlooked, yet who have shaped and formed the world we live in: Housewives, bureaucrats, but also engineers, cooperations, and collaborative endeavors. All those who have long been considered »remote« or »other«, be it geographically, ideologically, societally or all of the above. This applies just as much to the material - the archive - as it does to people or buildings. The inconspicuous (files, processes, institutional regulations), the non-normative format (oral histories, witnessing) or the lost, destroyed or never collected archives are places we need to search for, rather than continue to gloss over. We must focus on the less-read pages, the missing pages, the crumbling paper or the burnt books, and the files and archives that do not yet exist.

In my work, the material for these acts of construction and excavation is often paper. It serves not only as an archival object or as a record of events, but as a design object itself, as material for bureaucratic measures, and as regulations for curricula and teaching, the frictions and negotiations - the very material that constitutes architects and architecture on a large scale. Paper in architecture is the material on which worlds are imagined, altered, and forgotten. In fact, it is a material of worldmaking not just as fabulous paper architecture or beautiful drawing. Every archive constructs a view of the world, and every drawing rests on a pile of paper thoughts and discourses that came before it.

\section{Of Archives Forgotten, Destroyed, or Not Yet}

Paper serves as a clue or guide to evaluate what makes architecture and who makes and made architecture. To do that, we need to look beyond the »heroes" and analyze the innocent-looking paper stacks, the systems, the bureaucracy, the infrastructure - piles and piles of files. From proportions to standards, architects have repeatedly tried to not only prescribe form, but 
also exert social and political control. As rules were exported into material form, architecture became an accomplice in constructions of governance. But as we know, »Design Rules « are never neutral, and neither is the technological discourse accompanying their emergence. While typically viewed as a bureaucratic impediment, rules and codes are in fact societal expressions and aesthetic tools. Furthermore, attempts to maximize control through systems often produce unpredictable results. We must ask: What are the architectural, spatial, and political implications of design rules, whether prescribed or self-imposed? How have irrational tendencies been complicit in, or even instrumental to, the formation of design ruleshow design rules? And most importantly: what are the values inscribed in supposedly aesthetic or technological principles, whom do they benefit, and what assumptions are they based on? In short, when looking at norms, standards, bureaucratic measures, and administrative processes, I would argue that we must treat them as formal and political acts of Gestaltung - and critically probe their ideological intent and human consequence.

Looking at paper (literally), we can trace these questions, or rather, we can construct the paper trails that would otherwise remain hidden in plain sight. In my research on norms - taking the term's suspension between social modes of conduct and technical regulations as a basis for my questions I look, amongst other institutions, at the German DIN Institute (German Institute for Norms, founded under a different name in 1917). Emerging as a large-scale operation initially from a group of engineers, architects, and corporate lobbyists who tried (and still try) to define and design technical norms for literally every object in post-war Germany, in 1922 the institute issued (not coincidentally, I believe) the standardization of DIN A paper formats as the most successful norm of modern life. Paper, here, becomes both a subject of design and an object for designing, ruler and ruled, paper and file. Every painting, sketch, bureaucratic form and print has since fallen within its frame - approved and designed by engineers, mathematicians, and architects to make the world more homogeneous. Tolerances were minimized, dimensions fixed, and outlines drawn on page after page of (in turn) normed paper sheets, forming an ever-growing entourage of norms for all objects and aspects of life in post-World War I Germany.

All of this was done in the name of engineered transparency and the efficiency of technology - but not as a piecemeal process. The search for a transparent system of these almost self-proliferating norms was based on the idea of so-called »Ur-Normen« (foundational norms), a main obsession of 
the DIN from the very beginning. This was not a merely pragmatic attempt at regulating production, but an endeavor to systematize the world into a safe, predictable place after the first of two World Wars in the 2oth century. Architects and architecture were at the heart of these efforts, ready to rebuild, and re-imagine an ordered environment built upon the modernist dream of the tabula rasa.

Now, how does that relate to the question in the beginning of this essay: What do we see when we look at (modern) architecture? I would propose rethinking the question in the reverse: What makes the architecture we look at look like it does? Why can we see that architecture and not others? Why are we looking at it in the first place? While these sound like rhetorical exercises, I think we should take them quite literally. Who and what shaped the architecture of our canon? How did they get to that position, and what defined the insiders and outsiders of this canon; those who become known and those who get forgotten, those who could build, and those who were made to disappear? There cannot be one answer to such questions. Rather, we might suggest a strategy: look at what we don't see; bring the flickering blur into focus that lingers between the already written pages; record unheard voices, look between stacks, take files seriously. The regulations in place, the order imagined, or the systems constructed formed what we now know as "Modern Architecture in early 2oth-century Germany at least as much as aesthetics, or even economics - and definitely more broadly than individuals still often referred to as "geniuses«.

This question is by no means a purely historic one, but the archival traces of decision making and negotiation processes help trace aesthetic intentions interwoven with bureaucratic desires, showing time and again their interconnected, inevitable entanglement. At a moment when the design and distribution of information has become a dominant driver of world politics and the economy, the aesthetic and material implications of algorithmic thinking remains under-researched - as do concurrent shifts of agency. A history of proto-algorithmic thinking in the discipline of architecture and engineering is not a mere history of computation or the so-called »digital." Rather, looking at precedents and mechanics of algorithmic thinking in the pre-digital and pre-computational world by analyzing material objects and their design is indispensable in excavating the production of embedded values of - and through - contemporary information design; an urgent endeavor for both makers and (hi-)story-tellers. 
Germany's architectural history of the 2oth century has produced a vast literature - and yet, the role of the automation of Gestaltung (rather than production) in the construction of modernity in this specific cultural context is still to be assessed. Reviewing when the rhetoric of technological neutrality drove aesthetic and societal debates will reveal the entanglement of technocratic agency with processes of intentional form-giving. Located in the seams between what is conventionally called "architecture history" (monographic accounts or analysis of large-scale buildings) and the history of science and technology, looking for archives or constructing them through history writing becomes a foundational tool. Treating architectural thinking as inseparable from an aestheticized rationalism uncovers the aesthetic and epistemic convergence between seemingly opposed historical movements and actors. With my research, I hope to bring forth the urge to question a ready dichotomy of design and bureaucracy, and of "neutral « technology and morality. Placing a history of norms, of files, of bureaucratic thinking in spatial vicinity to the execution of architectural promises can unveil uncomfortable friction and productive affinities necessary for our histories to bear on the present.

To do that, we might need to construct the archive rather than find it: these are stories not derived from Gropius's letters, or Mies's drawings, but piles and piles of correspondence, ideas, processes, and documentation. As such, these archives can be built or written, recorded or forgotten, visual or sensual. By looking less at buildings and more at discussions, we might ask questions such as: What was the aim of architecture that focuses on technology and process, what happens to the subject? What does an architect like Walter Gropius hope to gain by making design automatic? What do the residents in his houses smell when the spring comes? Where is the hope for change embedded in both technological and aesthetic visions? And how did they negotiate forms and materials to get there?

\section{Architecture Histories: For Whom?}

When we, as historians and architects, go to »the archive« to conduct »research", I put those terms into quotes because (as we know) all archives are constructed, and research takes many forms and formats. Archives are materialized worldviews and we construct our histories from them.

If architecture has canons, archives reveal their becoming. Architectural design that architects are taught is never self-evident, and the absence of an 
underlying ideology of any canon illusory. They have precedent, they change and they must keep changing. Design and research (especially in a field so enchanted with the promise of technological prowess or innovation) is never neutral. We need critical historical and theoretical reflection to ask: How are we complicit as architects, historians, and teachers? How do we need to sharpen our tools, our terminology, and our methods to investigate how ideologies, forms, and power are constructed? How can we make critical reflection central to the field? Because what gets configured, normalized, and controlled by the stories from the archives are ultimately the subjects who occupy, use, and inhabit architecture.

So instead of asking "what, when, or where is the archive of architecture history« we need to dig through the very stuffleft on the wayside. We need to unearth and construct those archives that we are sorely lacking. We need to critically assess not only what is our history, but how our histories are constructed - by whom and, most of all, for whom. 